\title{
PERCALÇOS DA INTEGRAÇÃO LATINO- AMERICANA: ANÁLISE COMPARADA DOS REGIONALISMOS DAS DÉCADAS DE 1960, 1990 E 2000
}

\author{
MISHAPS OF LATIN AMERICAN INTEGRATION: A COMPARATIVE ANALYSIS OF \\ THE REGIONALISM OF THE 1960S, 1990S AND 2000S.
}

Roberto Teles Lima Barros

\begin{abstract}
Resumo
A literatura sobre integração latino-americana frequentemente aponta três "ondas" de regionalistas na região: as décadas de 1960, 1990 e 2000. Entretanto, ainda há percepções que o regionalismo latino-americano é "sem sentido" ou errático. O presente artigo busca, comparando esses períodos históricos, identificar que percalços são comuns na experiência temporal e se, ainda assim, houve avanços dentro da cooperação regional.

Palavres Chave Ondas de Regionalismo, América Latina, Integração Regional
\end{abstract}

\section{Abstract}

The literature on Latin American integration often points out three regionalistic "waves" in the region: in the 196os, 1990s, and 2000s. However, there are still some who claims that the Latin American regionalism is "meaningless" or erratic. The present article seeks to compare these distinct historical periods in order to assess what mishaps are common over the temporal experience and whether there has been- or not- progress in regional cooperation Key words: Waves of Regionalism, Latin America, Regional Integration

\section{INTRODUÇÃO}

A América Latina tem presenciado nas duas últimas décadas um crescimento quantitativo de organizações regionais para a resolução conjunta das limitações dos Estados. O fenômeno de instituições comuns e as discussões sobre a cooperação entre os Estados latino-americanos ganhou especial destaque com o surgimento de governos - principalmente na parte sul do subcontinente - que interpretam a intensificação das relações intrarregionais não apenas como uma maneira de se superar os desafios do desenvolvimento econômico, mas também como maximizador de sua margem de autonomia (BRICEÑORUIZ, 2011). Em meio a esse recente processo, surgiram instituições desde a Aliança Bolivariana para os Povos de Nossa América (ALBA), União das Nações Sul-Americanas (UNASUL e a Comunidade de Estados Latino-Americanos e Caribe (CELAC). 
Não obstante, mesmo tendo ganhado destaque na mídia e nos círculos acadêmicos, o fenômeno em si não é novo. Recorrente desde a década de 1960, os Estados latino-americanos mantêm em seu cerne estratégico a cooperação regional como um importante instrumento para a solução de seus impasses em relação ao desenvolvimento e às intempéries do sistema internacional. Tal tradição, assim posta, explica parcialmente a recorrência, do surgimento e manutenção de organismos regionais, partindo desde a Associação Latino-Americana de Livre-Comércio (ALALC), perpassando ao Mercado Comum do Sul (MERCOSUL), Comunidade de Andina de Nações (CAN) até as outras já supracitadas.

Assim como em muitos pesquisadores, surge uma questão ao observar tal quadro: que motivos podem ser apontados para que, mesmo com todos esses processos em vários anos, a integração latinoamericana não tenha avançado tanto como a europeia? Para Malamud (2011), essa questão é dada pela dificuldade que esses Estados têm tanto em ceder soberania a um organismo supranacional, bem como às instabilidades políticas presentes na região. Já para Sabatini (2014), essa difusão de instituições é a manifestação da falta de concordância e sobreposição de interesses entre os Estados, e não um sinal do aumento da cooperação, ou seja, não é fato que se evolui a integração, mas sim representa-se um fenômeno contrário. No ponto de vista desses autores, os processos de cooperação latino-americanos apresentaram resultados falhos quando se tem em perspectiva os avanços que supostamente se propõem e os resultados alcançados pela experiência europeia.

Entretanto, há uma problemática ao observar a integração latino-americana com lentes voltadas ao caso europeu, principalmente em dar-lhe um sentido teleológico. Mercedes Botto (2015), ao estudar o MERCOSUL e a cooperação regional, identifica, de fato, que a integração latino-americana é errática em certos processos, mas que atinge significados e resultados importantes, não apenas em termos de comércio, mas em harmonização de áreas de políticas públicas e interação social. Os resultados em si perpassam as expectativas imediatas de específicos governos, mas se enfatizam em setores específicos, em especial a cooperação na área de saúde e educação.

É a partir desse ponto que interessa entender quais são os estimuladores, condicionantes e obstáculos que a integração latino-americana tem enfrentado em uma análise de perspectiva histórica comparada. Essa maneira de análise nos permite observar, a partir dos pontos selecionados, não apenas as diferenças contextuais, mas também o que de semelhante houve nos processos, a fim de buscar nessas similitudes algumas generalidades e traçar o que de recorrente tem sido apontado como empecilho e ainda o que não foi claramente identificado.

Desse modo, parte-se para buscar que elementos comuns encontram as três ondas de integração latino-americana (anos 1960, 1990 e 2000) para sua conformação, em que se diferenciam e o que bloqueou o avanço. Foca-se em critérios específicos para alcançarmos os objetivos do presente artigo: a) contexto político internacional; b) ideias econômicas presentes e; c) política das elites locais perante o regionalismo. A escolha do método comparado é de lançar-se mão de necessária revisão bibliográfica perante a temática dentro do escopo proposto. A escolha das variáveis, por mais que pareça arbitrária, partem do conjunto da 
própria bibliografia, em que as mesmas são as principais condicionantes das políticas externa e regional, como apontam Thacker (2006), Kingstone (2011) e Jaguaribe (2008).

O primeiro critério permitirá uma visão necessária dos condicionantes sistêmicos que pressionam os agentes internos a tomar as decisões e, como já afirmado, geralmente impulsiona os países latinoamericanos à busca pela integração. O segundo está tanto interconectado com o primeiro quanto com o terceiro ponto. São também as ideias econômicas presentes que interpretam que tipo de integração se deve adotar ou, ao menos, que enfoque se deve ou não implementar. Peter Kingstone (2011) nota que na América Latina os modelos econômicos variam de acordo com a maior ou menor presença do Estado, reflexo que pauta também parte dos projetos de integração, principalmente os que mantém enfoque em comércio e desenvolvimento. E o terceiro e último ponto, das políticas das elites perante o regionalismo, trata de como esses atores locais manejam tanto as condicionantes externas, as ideias econômicas e as demandas internas para a decisão de como a integração e cooperação regional podem ser instrumentos úteis para seus interesses, bem como também o contrário: os blocos regionais serem ou se tornarem um empecilho para os seus interesses.

A partir do que foi exposto, a sessão seguinte analisará os aspectos citados relevantes aos processos de integração da primeira onda de integração latino-americana, os anos 1960. Como em todos os períodos foram levados a cabo, com maior e menor intensidade, projetos de cooperação e integração regional em toda a região latino-americana e cada um com suas especificidades, selecionamos para este período a ALALC, o Mercado Comum Centro-Americano (MCCA) e o Pacto Andino para maior apreciação, devido a suas relevâncias e correlação intrínseca, além de serem exemplos dos processos que ocorreram no período. A sessão posterior seguirá nos mesmos moldes, entretanto tratando especificamente da segunda onda integracionista na década de 1990, dando enfoque ao MERCOSUL, Tratado de LivreComércio da América do Norte (NAFTA, no acrônimo em inglês) ${ }^{1}$ e a Área de Livre-Comércio das Américas (ALCA). Essa terceira parte intentará mostrar as mudanças em relação ao período anterior nos três aspectos, bem como uma maior divisão regional em blocos hemisféricos. A quarta sessão tratará dos fenômenos da terceira onda integracionista dos anos 2000. Caracterizados como "regionalismo póshegemônico", serão tratados de maneira mais específica a ALBA, UNASUL, CELAC e como exemplos da experiência recente de processos de cooperação políticos e econômicos e como, mesmo com estímulos externos similares, a interpretação das elites locais modifica a ação e que tipo de cooperação deve prevalecer. Adiciona-se à análise do período dos blocos dos anos 2000 a observação acerca da Aliança do Pacífico, em especial por contrapor parte das experiências pós-hegemônicas dos processos acima. A última sessão será dedicada a breves considerações finais, onde fecharemos os balanços sobre os processos e identificaremos as similitudes e dissonâncias.

\footnotetext{
${ }^{1}$ Aqui coloca-se o NAFTA como latino-americano por dois especiais motivos. Mesmo que seja um processo Norte-Americano, há a presença do México como participante e a tentativa de ingresso neste acordo por parte da Argentina e suas repercussões nos anos 1990 pelo governo Menem. Por mais que seja questionável a sua localização como "latino-americano", suas consequências nos processos de regionalização dentro de todo o hemisfério são inegáveis.
} 


\section{A Primeira Onda: Regionalismo dos anos 196o}

\section{Contexto Internacional}

A primeira onda de regionalismo latino-americano foi fruto do contexto internacional firmado no pós-2 ${ }^{a}$ Guerra Mundial e postulado na Guerra Fria. Marcado para além do conflito Leste-Oeste, o período também apresentava um cenário de reformulação no centro do sistema, no qual se apresentava uma Europa ainda em reconstrução e necessidade de rearticulação regional para a busca de mercados e alternativas ao desenvolvimento. A falta de compradores aos produtos primários, a deterioração dos termos de troca e o crescente protecionismo no centro global representavam para a América Latina desafios para sua inserção no cenário internacional (BÉRTOLA, OCAMPO, 2015).

O plano hemisférico apresentava um recrudescimento dos Estados Unidos perante a segurança coletiva da região. Durante a década de 1960, a América Latina presenciou conflitos na América Central e Caribe, representativos disso a questão cubana e seu afastamento da Organização dos Estados Americanos, demonstrando que a alternativa soviética não era uma opção para os países da região, quando se tinha os Estados Unidos tão perto, ainda mais nesse período. Desse modo, sem poder recorrer para as grandes potências ou emergentes, o que restava como solução era a busca pela coordenação conjunta e parcerias com os vizinhos para alcançar mercados e escala de produção.

Outro ponto que fortalecia a ideia de que os países latino-americanos necessitavam de novos mercados era a impossibilidade e o não-auxílio dos Estados Unidos de suprir as necessidades comerciais e econômicas da região ${ }^{2}$. Não sendo diretamente foco estratégico de suas preocupações de segurança (excetuando alguns casos, como o cubano), os Estados Unidos contavam com grande capacidade militar e apoio dos governos locais, estes sendo mantidos em regimes de exceção. Assim, diferentemente de como houve na Europa e em países asiáticos - Japão e Coreia do Norte -, os Estados Unidos não financiaram ou promoveram projetos de investimento hemisférico, como a Operação Pan-Americana. Sem este apoio do centro do Ocidente capitalista e com problemas de alcançar mercados em outras regiões, restava apenas aos países latino-americanos buscar maneiras conjuntas de suprir essas necessidades comerciais e econômicas (BRICEÑO-RUIZ, 2011).

Ideias Econômicas

\footnotetext{
${ }^{2}$ Apesar da tentativa da "Aliança para o Progresso" no período, o montante em si foi menor que o aplicado na Europa e na Ásia, por conta, em especial, das necessidades dos Estados Unidos nos outros dois continentes (KINGSTONE, 2011).
} 
É difícil ao abordar a integração latino-americana sem citar o papel que teve, no momento inicial, a Comissão Econômica para América Latina (CEPAL) ${ }^{3}$ e os pensamentos de seu diretor Raúl Prebisch. Para Prebisch (2012), o sistema econômico global estava dividido entre centro desenvolvido produtor de manufaturas e uma periferia subdesenvolvida e exportadora de matéria prima e commodities primária; neste contexto, a solução para a periferia sair dessa situação que mantinha a tendência ao desequilíbrio seria a sua industrialização. Nesse sentido, cabia ao Estado um papel importante para o desenvolvimento de políticas de incentivo e proteção à indústria nacional, tomando forma no que se convencionou chamar de política de Industrialização por Substituição de Importações (ISI) ou Industrialização dirigida pelo Estado4 (SIMONOFF, 2012; BÉRTOLA \& OCAMPO, 2015).

Essa política de substituição de importações baseava-se na mudança da planta fabril de um país em que se tornava autônomo e termos produtivos, gerando protecionismo em setores deficientes da indústria e, quando amadurecidos, aberto gradualmente à competição gerando sua eficiência (KINGSTONE, 2011). Entretanto, não basta apenas o protecionismo e desvio de comércio se não houver um escalonamento da produção e a mudança da pauta exportadora. Nesse caso, a integração ganha um papel chave, em que se pode gerar, diante de uma zona produtiva comum, o escalonamento da produção, uma área de demanda e consumo maior, bem como harmonização de políticas macroeconômicas que privilegiasse o comércio intrazona no início e, posteriormente, a abertura para o mercado global.

Jaguaribe (2008), Prebisch (2012) e Puig (1983) ${ }^{5}$ enxergavam no período a solução do desenvolvimento econômico via integração como a solução mais razoável apresentada conforme se dava o cenário global. A autonomia dos países latino-americanos só se daria na medida em que suas elites locais buscassem diminuir suas relações de dependência com os Estados Unidos e países centrais a partir da conformação conjunta de políticas comuns que privilegiassem a cooperação e a geração de cadeias produtivas comuns. Era a maneira mais viável que a proposta de uma autonomia secessionista, como nos põe Puig, já que sair do sistema capitalista naquele período poderia gerar altos custos internos e externos, como nos mostra o exemplo cubano.

Dessa maneira, as ideias econômicas do período enxergavam no Estado o promotor do desenvolvimento e dinamizador do mercado naqueles países em que o as condições econômicas ainda se caracterizavam deficientes ou em dificuldades de auto-gestão para a promoção da industrialização, vide investimentos ou protecionismo. Se por um lado ia de encontro com o credo ortodoxo do livre-mercado, ao mesmo tempo encontrou crítica de economistas de cunho marxista, que enxergavam no modelo cepalino-desenvolvimentista uma maneira de perpetuar o modelo capitalista e não de superá-lo. Era visto mais como uma adequação do sistema e não de fato uma mudança (SIMONOFF,2012).

\footnotetext{
3 Ainda que criada em 1948, a CEPAL ainda segue produzindo artigos e recomendações para os países da região, mantendo sua relevância sobre a temática política e econômica na região.

4 Bértola e Ocampo (2015) questionam a adoção da tipologia para a política econômica do período como ISI. Os autores sugerem a nomenclatura Industrialização dirigida pelo Estado tendo em vista a manutenção do grau de intensidade de importações em muitos países da região, em especial na forma de bens de capital.

5 Mais que a questão econômica, Puig enxergava na cooperação política o principal meio de se lograr a autonomia se comparado a Jaguaribe e Prebisch.
} 
A ideia de promoção autônoma e de desenvolvimento de uma indústria forte nacional teve aceitação nas elites regionais nesse período, principalmente pelo cunho nacionalista de governos tanto populistas quanto de regimes ditatoriais. Entretanto, esse mesmo nacionalismo mostrou-se obstáculo para a outra metade dos planos de desenvolvimento, como a cooperação econômica, abertura econômica e harmonização macroeconômica. A adoção parcial de ideias e interesses individuais dos Estados também trouxeram limites ao desenvolvimento das instituições.

\section{Política das Elites Locais perante o Regionalismo}

Como Soderbaum (2015) nos aponta, é problemático categorizar a primeira onda do regionalismo latino-americano de regionalismo fechado. O principal exemplo dessa problemática é a conformação da ALALC, em 1960 com o Tratado de Montevideo. Conformado por Brasil, México, Uruguai, Argentina, Peru, Paraguai e Chile, esse bloco regional estabelecia a queda das tarifas comerciais entre os membros do bloco, buscando-se avançar para o aprofundamento da integração a partir do avanço da cooperação produtiva. Entretanto, esse projeto tinha duas linhas antagônicas que disputavam e geravam entraves na conformação política do bloco. Os países em menor grau de desenvolvimento relativo insistiam para um avanço em direção à formação de um mercado comum, que diminuísse as assimetrias entre os paísesmembros e que harmonizasse as políticas econômicas. Não obstante, os países de maior tamanho econômico travaram esse avanço, preferindo a formação de uma área de livre-comércio que permitisse uma entrada melhor de seus produtos a mercados menos competitivos.

Desde aí recorre o primeiro ponto de conflitos de interesses e práticas que impediram o avanço da ALALC. Para os países de maior mercado, era vantajoso a expansão de suas empresas, entretanto, não necessariamente uma harmonização de suas políticas com a de outros países, tampouco a geração de uma cadeia produtiva regional. Já para os países menores, havia a problemática de desvio de comércio ao ter de comprar preferencialmente produtos mais caros dos seus vizinhos em revelia aos similares de outros países (KINGSTONE, 2011). Sem a homogeneização de interesses e de se aprofundar a integração, a estratégia da ALALC, em maneira mais ampla, acabou tornando-se mais uma forma de acordos multilaterais preferenciais de comércio que um processo de integração produtiva, dando em sequência a transformação para ALADI, nos anos 1980.

Devido a esse processo de deficiência e avanço na ALALC, os países andinos decidiram por incrementar seu processo de integração pela via do Pacto Andino, em 1969. O Pacto, formado por Peru, Chile, Venezuela (a partir de 1973), Bolívia, Equador e Colômbia buscava avançar mais que a ALALC, espelhando-se na experiência supranacional europeia. Nesse sentido, ampliou-se o espectro livrecambista que predominava nos grandes países da ALALC e buscou, a partir da criação de organismos multilaterais, implementar um desenvolvimentismo dirigido e planejado, com menos assimetrias (BRICEÑO-RUIZ, 2011). Entretanto, se o problema da ALALC foi a questão dos interesses dos países, o Pacto sofreu do esvaziamento progressivo de seus membros. Em 1976, o Chile, no regime Pinochet, saiu do acordo, a partir de uma concepção econômica mais ortodoxa e liberal, não insistindo no 
intervencionismo e protecionismo do próprio bloco. Mesmo assim, o grupo avançou, criando sua própria Corte e Parlamento e com crescente aprofundamento. Mesmo assim, com as crises derivadas dos anos 1980/1990, o grupo sofreu mais uma retirada, dessa vez sendo o Peru, e posteriormente a Venezuela.

Se na América do Sul o processo avançava a passos curtos, na América Central o Mercado Comum Centro-Americano (MCCA) já trazia maiores avanços e importantes resultados em seu período inicial. Mais ambicioso que a ALALC, o bloco formado por Costa Rica, El Salvador, Guatemala, Honduras e Nicarágua trouxe desde o próprio Parlamento e Corte, até a liberação comercial total intra-bloco para produtos produzidos dentro do limite geográfico intrazona. O resultado dado inicialmente foi o aumento do fluxo de comércio dentro dos países bem como um significante aumento no investimento estrangeiro direto, proveniente majoritariamente dos Estados Unidos. Esse processo, mesmo gerando uma diversificação produtiva e atraindo empresas estrangeiras para a produção interna, não deu espaço para a geração de indústrias de caráter nacional, sofrendo o bloco com grande evasão de divisas e "refém" das decisões das matrizes das empresas estrangeiras (ALEIXO,1984).

Vale acrescentar que o nacionalismo e a instabilidade interna dos Estados influenciaram o próprio avanço dos blocos. As sequências de golpes militares e revisionismos das políticas econômicas de países como Chile e Brasil, impediram avanços mais retilíneos no Pacto e na ALALC, por exemplo. No caso do MCCA, as querelas internas em relação ao crescimento desigual dos países, bem como os conflitos bélicos entre os membros, impediram a conformidade de políticas e avanços nos entes conjuntos, adicionando-se ainda assim o fator da presença de empresas estrangeiras usufruindo do espaço de livre-comércio. Esse mesmo quesito era presente na América do Sul, em que o papel das empresas estrangeiras junto com as elites locais impedia a coordenação conjunta com as outras dos outros países para formação da integração produtiva, além da dificuldade de harmonizar interesses de países como México e Argentina, Uruguai e Paraguai (BRICEÑO-RUIZ, 2011). Assim, os planos regionais e o desenvolvimento associado encontraram na barreira do nacionalismo e dos interesses individuais parte dos impeditivos para o seu avanço.

\section{A Segunda Onda: Regionalismo dos anos 1990}

\section{Contexto Internacional}

A situação sistêmica nos anos 1990 apresentava-se muito distinta à da primeira onda, entretanto não menos desafiadora para os países latino-americanos. Com a dissolução da União Soviética e fim da Guerra Fria, os Estados Unidos e o sistema capitalista eram dados como vencedores, declarava-se o fim da era das superpotências e o início do período da unipolaridade. Sem a disputa sistêmica entre o Leste e o Oeste, o capitalismo avançava rapidamente pelos países da antiga cortina de ferro, trazendo à tona outros atores do sistema: as grandes empresas, o mercado financeiro e as organizações transnacionais. 
Além da modificação na geografia do poder, os avanços nas telecomunicações e o barateamento dos preços dos transportes facilitavam o intercâmbio comercial, bem como o deslocamento de fatores de capital e investimentos. Essa mobilidade apresentava a necessidade de regimes mais flexíveis e de menores impeditivos que os fortemente protegidos e regrados pelo Estado, pressionando a uma desregularização do sistema financeiro e produtivo internacional. Assim se deu o avanço da globalização, em que se encurtaram as distâncias e os custos de produção em um sistema cada vez mais interdependente (GILPIN, 2001).

No plano hemisférico, caracterizava-se a queda dos regimes ditatoriais e a ascensão de democracias pelo continente americano desde a década de 1980. Além disso, com a hegemonia estadunidense estabelecida em âmbito global, restou aos países latino-americanos seguirem, após passarem por diversas crises, o receituário proposto pelos EUA em 1989 chamado Consenso de Washington. Nesse receituário, estabelecia-se medidas econômicas e administrativas que os países deveriam seguir para melhor se adequarem às novas demandas do sistema internacional e saírem de seu estado de penúria. Dentre essas propostas, encontravam-se cortes nos gastos públicos, privatizações e combate forte à inflação, privilegiando o cumprimento dos contratos internacionais e pagamento das dívidas (CORONADO, 2005). Estava dado o início da hegemonia do pensamento neoliberal que percorreu os anos 1990 na América Latina.

\section{Ideias Econômicas}

O neoliberalismo dos anos de 1990 que se pregou na América Latina veio como uma forte crítica ao modelo de substituição de importações, bem como ao Estado interventor e "inchado" de gastos públicos. A queda do modelo anterior iniciou-se nos anos de 1970 com a crise do padrão ouro-dólar, bem como com as crises posteriores do petróleo, ambas gerando o aumento dos juros nos países periféricos, além da geração de altos índices de déficit e necessidade de tomar recursos de bancos e instituições financeiras internacionais para equilibrar a balança de pagamentos (GILPIN, 2001). Como apontado anteriormente, a solução passava pela "correção" de rumos, a fim de conter o aumento dos gastos estatais e honrar o pagamento das dívidas.

Kingstone (2011) nos aponta bem o receituário proposto e adotado nos países latino-americanos, apresentando maior ou menor grau de intensidade. O equilíbrio das contas dava-se pelo corte de gastos públicos, privatizações de empresas públicas, contenção da inflação, por meios de aumento de juros, além da necessidade de estabilização cambial dos países. Além disso, preconizava a abertura dos mercados que antes gozavam do protecionismo. Essa abertura tornaria livre e competitivo o mercado anteriormente ineficiente e distorcido, no qual o desenvolvimento do mesmo traria uma melhor alocação dos recursos e, por conseguinte, a queda de preços, ajudando na contenção da própria inflação.

A vertente neoliberal também influenciou as correntes teóricas da integração regional, dando ênfase ao regionalismo aberto. Diferentemente do "antigo" regionalismo, o regionalismo aberto trazia 
menores amarras institucionais, sem a necessidade de organismos supranacionais ou de medidas vinculativas profundas. A integração poderia ser dada apenas em sentido instrumental, sem necessidade de avanços à supranacionalidade (SODERBAUM, 2015). Na América Latina, refletiu-se nesse pensamento no nascimento de blocos com ênfase estritamente comerciais, como o NAFTA ou o CAFTA, em que só se pautavam nas negociações as quedas tarifárias e resoluções de controvérsias relacionados aos contratos.

A palavra-chave que definia a utilidade da integração era competitividade e inserção internacional. A ampliação de redes de livre-comércio que um Estado tivesse permitia maior acesso a outros mercados e ao maior intercâmbio de bens e serviços, estimulando a competitividade e eficiência. Se na onda anterior o que movia era a necessidade e a vontade de industrializar-se e de buscar mercados, nesse "novo" regionalismo, mantinha-se primariamente a ideia apenas dos mercados.

\section{Política das Elites Locais perante o Regionalismo}

Apesar da homogeneização das ideias liberais, os graus de aplicação das mesmas foram distintos de acordo com o país e como as elites, econômicas e políticas, interpretavam tais adoções. Se por um lado, no México a liberalização foi intensa e ampla, no Brasil o processo deu-se com mais ressalvas, preocupando-se com os efeitos que teria nas indústrias nacionais em um regime livre de proteção (CARMO, 2013). É nesse arranjo e diferenciação da interpretação das elites locais que demonstram, principalmente, as diferenças entre processos do MERCOSUL e o NAFTA.

O MERCOSUL, constituído inicialmente por Paraguai, Uruguai, Brasil e Argentina, foi fruto das conversações iniciais entre Brasil e Argentina nos anos de 1980, em que ambos passavam por um processo de redemocratização. Com o avançar das negociações e conversações, o tratado que inicialmente versaria sobre a cooperação nuclear, ampliou-se em proposta e em membros, dando espaço para a conformação do MERCOSUL, uma União Aduaneira com ambições de se tornar um Mercado Comum. O que parece antagônico e curioso é a formação do MERCOSUL, em 1992, num processo em que imperava o neoliberalismo e a ideia de livre-mercado. O projeto do MERCOSUL não necessariamente era apenas vinculado à ideia livre-cambista, que teve seus maiores avanços nos anos iniciais, mas cuja composição de uma União Aduaneira (ainda que incompleta), trazia resquícios dos ideais dos modelos dos anos 1960. Segundo Mello (2002), essa permanência de paradigma traz a ideia de encapsulamento do bloco, em que serve como um apoio para o ganho de peso brasileiro perante as negociações internacionais, servindo em um jogo de duas medidas: acesso de mercados e ganho de relevância política.

Já o NAFTA, acordo firmado entre México, Estados Unidos e Canadá em 1994, responde estritamente aos anseios neoliberais do período, em que se tem um tratado amplo que abrange propriedade intelectual, liberalização comercial e modelos de resolução de controvérsia que trata diretamente empresa-Estado (CORONADO, 2005). Segundo Santos (2007), Carlos Salinas, então presidente mexicano, chegou a afirmar que a entrada do México no bloco era o primeiro passo do país em direção ao primeiro mundo. A ideia de que um acesso amplo ao maior mercado norte-americano não 
apenas animou o México no período, mas também o Chile e a Argentina, que durante os anos 1990 pediram acesso ao bloco, apesar de terem sido negados.

Com esse amplo apoio ao NAFTA, é levado a cabo dos meados de 1990 a 2005 a iniciativa da ALCA, uma zona de livre-comércio que envolveria toda América. As discussões, que já eram realizadas desde o governo Bush em 1990, ganharam reforço durante o período Clinton e com relativo apoio das elites locais. Entretanto, como afirma Carmo (2013) e Santana (2001), um dos principais entraves à ALCA foi o governo brasileiro de Fernando Henrique Cardoso, que respaldava os interesses da elite industrial brasileira que não tinha condições de competir com os seus concorrentes estadunidenses e canadenses. Assim, com a estratégia de negociar em bloco e de mudar o enfoque inicial de uma rede de acordos bilaterais para um amplo acordo multilateral, o governo brasileiro logrou a protelação e adiamento das negociações, protegendo o avanço do projeto, que veio a ser suspenso em 2005 por falta de acordo.

É interessante notar que o papel das elites locais variava de acordo com o grau de resiliência que as ideias econômicas tinham, bem como da força delas dentro do aparato Estado, definindo o seu poder de barganha. Nesse sentido, a experiência dos anos 1990 trouxe importantes resultados, como tratados que até hoje vigoram e que ganharam novos significados e importância a partir dos anos 2000. Ao mesmo tempo, as consequências econômicas advindas da austeridade e crises provocadas pela ortodoxia econômica refizeram, a posteriori, voltar conceitos sobre o papel do Estado e sua existência para diminuir as assimetrias geradas pelo mercado, bem como uma revisão do que vem a ser o papel da integração regional.

\section{Terceira Onda: Regionalismo dos anos 2000}

\section{Contexto Internacional}

Dos três contextos aqui apresentados, talvez esse tenha sido o mais favorável para os países latinoamericanos em termos materiais e de oportunidades. A primeira década do século XXI representou uma relativa mudança estratégica dos Estados Unidos, em que se voltou para embates no Oriente Médio e na Ásia, tanto em termos bélicos, na invasão contra Afeganistão e Iraque, bem como em termos comerciais (RIGGIROZI, TUSSIE, 2011). O período representou a ascensão dos emergentes, pautado no crescimento de países como China e Índia, que aumentou o consumo de commodities primárias e, consequentemente, o preço desses bens, vastos na região e facilitando os superávits que financiariam as inciativas de integração dessa década ${ }^{6}$.

\footnotetext{
6 O grau de crescimento econômico médio da região latino-americana em produto interno bruto, segundo o Banco Mundial, durante os anos 2000 foi de 3,66\% ao ano. A recorrência dessa média nos anos de crescimento foi superior aos $2,78 \%$ dos anos 1990 e $2,06 \%$ dos anos 1980 . O aumento em 31\% do crescimento médio em relação à década anterior possibilitou maior capacidade financeira para o ensejo de projetos regionais.
} 
O distanciamento dos Estados Unidos nas questões regionais deu margem para o surgimento do regionalismo pós-hegemônico ou pós-liberal. Segundo Tussie e Riggirozzi (2011), esse regionalismo, caracterizado pela terceira onda, é pautado em termas que extrapolam do comercial e industrial, baseando-se em outras perspectivas de cooperação, como cultura, educação, saúde, segurança e defesa7 . A ampliação das temáticas também tem a ver com a ascensão de regimes de esquerda e centro-esquerda na região, cuja crítica ao modelo neoliberal dos anos 1990 também faz ressurgir o do Estado como promotor do desenvolvimento.

\section{Ideias Econômicas}

A crítica ao neoliberalismo trouxe duas tendências que definiram os rumos dos processos de integração dos anos 2000. O primeiro deles é concernente ao papel do Estado na economia. Mesmo que tenha sido de adoção parcial ou gradual, o período em que o neoliberalismo se instaurou trouxe fortes consequências em muitos Estados latino-americanos, como aumento do desemprego, manutenção do desequilíbrio das contas públicas e sucateamento dos serviços públicos (KINGSTONE, 2011). Aliado a essa questão, a ineficiência administrativa resultou em crescente tensões entre cidadãos e governantes, no qual as concessões a empresas privadas não atendiam às demandas e pouco o Estado podia fazer, como se pode exemplificar pela privatização das plantações de milho no México ou da água na Bolívia (SANTOS, 2007). Desse modo, a intervenção estatal significaria a volta do poder público para sanar os desequilíbrios gerados pelo mercado, uma readequação dos serviços públicos frente à crescente desigualdade na região (KINGSTONE, 2011).

O segundo ponto foi a ascensão dos governos de esquerda e centro-esquerda críticos à lógica neoliberal na região, como efeito das crises na região durante os anos 1990, como a crise do efeito Tequila em 1994/95. Esses governos e novas elites políticas reinseriram no jogo de promoção dos seus objetivos governamentais e de desenvolvimento as empresas e os investimentos estatais, participantes ativos na promoção da política externa e regional desses países. O uso da máquina pública para a promoção de empresas nacionais ou para a cooperação regional não é novo, mas é resgatado por esses governos, principalmente sob o discurso de auxílio e solidariedade (CORONADO \& ALEJO, 2013).

Assim, como resultante dos bons saldos da balança comercial que apresentavam, os Estados latino-americanos, principalmente Brasil e Venezuela, inverteram a lógica do controle de gastos para o de expansão de gastos tanto no âmbito interno como para a promoção de seus países no exterior (CARMO, 2013). Nesse sentido, no espaço doméstico, buscou-se ampliar o mercado interno e diminuir a desigualdade social, com política de reversão de renda e, no âmbito externo, promover alianças e negócios

\footnotetext{
7 Com exceção do Tratado Interamericano de Assistência Recíproca (TIAR), que surgiu como escudo legal para a interferência estadunidense no hemisfério durante a Guerra Fria, a criação do Conselho de Defesa Sul-Americano, mesmo que com suas limitações, marca o primeiro projeto sem a presença dos Estados Unidos que aborda os temas de segurança e defesa de modo amplo entre os governos dos Estados.
} 
com auxílio e empréstimos estatais, financiando o processo de internacionalização de empresas e de poder.

\section{Política das Elites Locais perante o Regionalismo}

Alejo e Coronado (2013) apontam, ao analisarem a CELAC, três grupos de países que podem muito bem ser análogos às elites políticas que os conformavam e aos projetos de integração que os mesmos propunham. A primeira delas é subordinada ao modelo neoliberal ortodoxo, encabeçada pelo México e suas aspirações geopolíticas de se converter em um pivô entre o Norte e o Sul, com a presença de países como Colômbia e Chile em suas iniciativas, principalmente pela Aliança do Pacífico. A segunda, caracterizada por eles como pós-neoliberal, com preponderância do Brasil e de suas aspirações de se converter em uma potência regional, com base na construção de relações Sul-Sul, com vínculos subregionais a partir dos acordos da UNASUL e do MERCOSUL. A última é a contra hegemônica, liderada por Venezuela, cujas alianças com Cuba, Equador e Bolívia mantém no seu cerne a base das relações Sul-Sul, entretanto, com posicionamento de questionamento à hegemonia dos países centrais, principalmente a estadunidense, cujos países participam da ALBA.

O posicionamento e surgimento da UNASUL foi um importante instrumento de ação política durante o governo Lula e no início do período Dilma, onde se buscou a afirmação do país como protagonista da região no cenário internacional e fortalecendo o seu papel de emergente (SPEKTOR, 2011). Com o seu início vinculado à resolução de conflitos entre Venezuela e Colômbia, a UNASUL acoplou e ampliou vários organismos regionais de consulta e cooperação em diversas áreas, bem como conformou o primeiro bloco político a unir todas os Estados sul-americanos. Com uma função que vai desde a mediação de conflitos a investimentos em infraestrutura, tendo seus principais gabinetes o Conselho de Defesa Sul-Americano (CDS) e o COSIPLAN (antigo projeto da Iniciativa para a Integração da Infraestrutura Regional Sul-Americana - IIRSA - acoplado ao organismo), dando autonomia de ação aos membros e mantendo afastado os Estados Unidos de suas decisões.

Entretanto, mesmo com a presença de todos os países, a UNASUL ainda carece de certos poderes. Malamud (2011) aponta a falta de consenso sobre a liderança brasileira como um empecilho ao desenvolvimento do organismo regional, bem como usa relutância para ser paymaster e a efemeridade do bloco que não gera uma sessão de soberania, o que deixa os Estados sem compromissos, tornando-se mais um bloco de consultas. Além disso, os seus principais instrumentos contam com dificuldades de harmonização de interesses, como o próprio Conselho de Defesa, que detém países com bases estadunidenses e outros com discurso antiamericano, além da própria proposta do COSIPLAN ser burlado pelos financiamentos bilaterais do Brasil aos outros países via BNDES (SANTOS, 2013).

Na questão de homogeneidade de políticas, a ALBA apresenta interesses e uso de práticas mais coordenadas que a própria UNASUL. O projeto, liderado pela Venezuela chavista, apresentou um novo ponto de integração, em que não se vinculava territorialmente e pouco se baseava apenas nos 
intercâmbios comerciais. O projeto abarca concepções de desenvolvimento para além do comercialindustrial, no qual a solidariedade era a palavra-chave. Nessa questão, a ALBA abarcou diversos projetos sociais, focados principalmente em educação e saúde, além da promoção de um sistema de compensação comercial que não necessitava divisas caso não houvesse como faturar as dívidas, podendo-se utilizar bens para complementar a transação (TUSSIE, 2014). Essa era a proposta contra hegemônica do projeto bolivariano, em que buscava alternativas à concepção capitalista de desenvolvimento e de funcionamento (TORO, 2011). Entretanto, essa lógica perdurou até quando o capital venezuelano advindo do petróleo durou e, com a queda do preço do petróleo e a conseguinte crise que se instaurou no país, o projeto estagnou (BOTTO, 2015).

E, entre esses eixos que buscavam uma aliança mais política, outro bloco surgiu a partir da necessidade de se avançar nas pautas econômicas. México, Peru, Chile e Colômbia avançaram no projeto da Aliança do Pacífico, cujo objetivo é fortalecer e unificar seus mercados para torna-los mais atrativos e competitivos para os Estados asiáticos (BERNAL-MEZA, 2015). Com a reintrodução do debate neoliberal de livre-comércio na região, alguns interpretaram que tal bloco adveio para contrabalancear 0 protagonismo brasileiro e as propostas do ALBA (NOLTE \& WEHNER, 2013), bem como os que creem que se gerou o "cisma do Pacífico" na região, agindo de modo contraproducente para a integração na região sul-americana (FIORI, 2013). Entretanto, mesmo com essas questões apontadas, é interessante notar que a iniciativa vem com o objetivo de também diversificar parceiros e forcar-se na Ásia, que ampliou seu comércio com a região enormemente no período. Além de que há quem aponte que haveria uma possível disputa regional entre Brasil e México (NOLTE \&WEHNER, 2013) pelo mercado sul-americano. Tais interpretações advém da necessidade e da inciativa mexicana de diversificar sua pauta comercial em termos de parceiros, dado em conta sua dependência com os EUA.

Mesmo com divergências que refletem as características políticas das elites dos países que os compõem, os blocos dos anos 2000 apresentaram diversidade em termos de abordagens e conteúdos tratados, sem renegar os outros já criados. Tal questão se reflete na ampliação e manutenção do MERCOSUL e sua ressignificação com a ampliação de suas políticas sociais (BIZZORERO, 2011), bem como a ainda existência da ALADI e da Comunidade Andina de Nações.

\section{Considerações Finais}

Tendo em vista a diversidade de iniciativas integracionistas apresentadas, pode-se afirmar que a integração latino-americana é um fracasso? De acordo com a pesquisa realizada, observa-se que, apesar de autores como Sabatini (2014) e Malamud (2012) considerarem a reprodução de instituições como um sinal da falência dos projetos anteriores ou de sua insignificância, a experiência latino-americana mostra que muitas instituições sobrevivem aos percalços e que há uma preferência aos Estados em manterem os canais de contatos abertos ao invés de retroceder e fechar as instituições. Entretanto, ainda que não avancem da maneira que por vezes se prevê, é inadequado afirmar taxativamente o fracasso ou impossiblidade. O correto seria buscar entender onde, como e para quem essas tentativas de 
regionalização funcionam e se organizam, entendo os sues papeis de acordo com o período em que se é analisado.

Como fruto de nossa análise temporal, podemos notar algumas generalidades sobre a integração latino-americana tal como aqui fora apresentada. O primeiro é que as condicionantes sistêmicas têm uma grande influência para encorajar os Estados a buscarem a cooperação e por vezes a integração. Em momentos de crise ou dificuldades econômicas, busca-se a integração desse viés, buscando ampliar mercados. Nos momentos mais favoráveis, apresentou-se um enfoque mais político ao processo de integração, buscando superar as deficiências em outras áreas. O segundo ponto é a ida e vinda da presença do papel estatal no desenvolvimento. As políticas do período analisado apontam para um padrão de intervencionismo, seguido por políticas pró-mercado como solução para a crise gerada no modelo anterior e seguido por uma nova onda intervencionista após os problemas gerados pela ortodoxia. Hoje, podemos notar uma volta ao padrão em discurso para as propostas liberais, bem como em um contexto de crise regional, a volta de diálogos sobre a flexibilização do MERCOSUL e fortalecimento da Aliança do Pacífico (SIMONOFF, 2016).

O terceiro e último ponto merece especial atenção. Em muitos dos projetos de integração analisados, as instabilidades políticas e institucionais dos países minaram o avanço dos blocos regionais. Não é um fator isolado e determinante, mas é um padrão que, seja nos anos 1960, em que governos eram trocados por golpes militares ou nos anos 2000, em que governos são trocados por processos institucionais, a mudança abruta de regime e/ou governo e as instabilidades institucionais existentes criam mudanças no decorrer do processo. Mais do que a simples sessão de soberania, a estabilidade institucional doméstica é o que mais se ausenta dentro dos exemplos aqui abordados.

* Artigo recebido em 13 dez 2017, aprovado em 03 mai 2018.

\section{REFERENCIAS}

ALEIXO, J. C. B. (1984). Mercado comum centro-americano. Revista Informativa Legislativa. Brasília: UNB, a. 21, n. 81 .

BERNAL-MEZA, R. ALIANZA DEL PACÍfICO versus ALBA y MERCOSUR: Entre el desafío de la convergencia y el riesgo de la fragmentación de Sudamérica (2015). Pesquisa \& Debate. Revista do Programa de Estudos Pós-Graduados em Economia Política. 1, v. 47. 
BÉRTOLA, L. \& OCAMPO, J. A (2015). O Desenvolvimento Econômico da América Latina desde a Independência. Rio de Janeiro: Elsevier.

BIZZOZERO, L (2011). América Latina a inicios de la segunda década del siglo XXI: entre el regionalismo estratégico y la regionalización fragmentada. Revista Brasileira de Política Internacional, vol. 54.1.

BOTTO, M (2015). Introducción a la problemática: la integración regional en América Latina: ¿quo vadis?. In: BOTTO, M. Teoría y práctica de la integración latinoamericana: EI MERCOSUR bajo la lupa. Editorial de la Universidad de Buenos Aires, Buenos Aires, pág.18-44.

BRICEÑO RUIZ, J (2011). La integración regional en América Latina y el Caribe. Mérida: Codepre.

CARMO, C. A. (2013). A. A América do Sul, a China e as contradições da política econômica externa do Brasil. In: CARMO, C. A.; WINAND, E. C. A.; BARNABÉ, I. R.; PINHEIRO, L. M. (org.). Relações Internacionais: olhares cruzados. Brasília: FUNAG, p. 129-161.

CORONADO, J.P. \& ALEJO, A. F (2013). La Comunidad de Estados Lationoamericanos y Caribeños (CELAC); integración 'post-neoliberal', neoliberal ortodoxa y contrahegemónica. In: FLORES, C.S.; MARTINS, C.E. (org.). Nuevos Escenarios Para La Integración En América Latina. Editorial Arcis: Santiago, , p. 187-214.

CORONADO, J. (2005). México Ante la Dinámica del Poder Global: Proyección Geopolítica Externa e Interna. In: AYERBE, L. F. et al (org.). Integración Latino-Americana e Caribenha., p. 153-198.

FIORI, J. L. C. (2013) O Brasil e seu "Entorno Estratégico" na Primeira Década do Século XXI. In: SADER, E (org.). 10 anos de Governos Pós-Neoliberais: Lula e Dilma. Rio de Janeiro: FLACSO, p. 31-53.

GILPIN, R (2001). Global political economy: Understanding the international economic order. Princeton University Press.

JAGUARIBE, H (2008). "Autonomia e hegemonia no sistema imperial americano (1987)", In:

JAGUARIBE, H. Brasil, mundo e homem na atualidade: estudos diversos. Brasília: Fundação Alexandre de Gusmão, pg. 163-209.

KINGSTONE, P. (2011). The political economy of Latin America: reflections on neoliberalism and development. London: Routledge.

MALAMUD, A (2011). A leader without followers? The growing divergence between the regional and global performance of Brazilian foreign policy. Latin American Politics and Society, 53(3), p. 1-24.

MALAMUD, C (2012). La Alianza del Pacífico: un revulsivo para la integración regional en América Latina. Documento ARI, v. 46. 
MELLO, F. C. (2002). A Política Externa Brasileira e os Blocos Internacionais. São Paulo em Perspectiva. São Paulo, Fundação SEADE, v.16, n.2.

NOLTE, D. \& WEHNER, L. (2013). The Pacific Alliance Casts Its Cloud over Latin America, Hamburg: GIGA Institute.

PREBISCH, R (2012). El desarrollo económico de la América Latina y algunos de sus principales problemas. CEPAL: Santiago, 2012.

PUIG, J. C (1983). Malvinas y Regímen Internacional. Buenos Aires: Ediciones DePalma.

RIGGIROZZI, P. \& TUSSIE, D. (org) (2012). The rise of Post-Hegemonic Regionalism. The case of Latin America. London: Springer.

SABATINI, C (2014). Meaningless Multilateralism. Foreign Affairs (on-line).

SANTANA, H. R. P. (2001). Grupos de Interesse e a Política Externa Brasileira para a ALCA. Contexto internacional, 23(1), 167 .

SANTOS, M (2007). O México como aliado dos EUA no projeto de integração das Américas. Revista Brasileira de Política Internacional: Brasília, v. 2, p. 146-161.

(2013). A presença brasileira na América do Sul: ações e instrumentos de política externa. Análisis Político: Bogotá, v. enero-abri, p. 195-210.

SIMONOFF, A (2012). Teorías en movimiento: Los orígenes disciplinares de la política exterior y sus interpretaciones históricas. Rosario: Prohistoria.

(2016). Giros en las estrategias de inserción argentina a partir de la presidencia de Mauricio Macri. Conjuntura Austral, 7(37), 40-51.

SODERBAUM, F (2015, draft). Early, Old, New and Comparative Regionalism: The Scholarly Development of the Field.

SPEKTOR, M (2011). O regionalismo do Brasil. In: Bernardo Sorj; Sergio Fausto. (Org.). Brasil e América do Sul: Olhares Cruzados. Rio de Janeiro: Centro Edelstein de Pesquisas Sociais, p. 141-172

THACKER, S. C. (2006). Big business, the state, and free trade: Constructing coalitions in Mexico. Cambridge University Press.

TORO, A. (2011). El ALBA como instrumento de "soft balancing". Pensamiento propio, 33, pp.159-183. 
TUSSIE, D., (2014). Reshaping regionalism and regional cooperation in South America. Pensamiento propio, 39. 